\title{
Blood \& Couture: Dracula by Eiko Ishioka (石岡 瑛子)
}

\author{
Roberto C. RODRIGUES ${ }^{1}$
}

In this paper, through a bibliographical research and debate, we intent a filmic and artistic analysis of the feature film 'Bram Stoker's Dracula' (Francis Ford Coppola, 1992), specifically its costume design, signed by the Japanese designer and art director Eiko Ishioka 石岡瑛子 (1938 - 2012). The film's critical reception as well as its consequent elevation to a 'canon' status among the adaptations of the homonymous novel by Bram Stoker were taken into consideration. This paper proposes a new approach of Ishioka's costume design legacy, that flirts significantly with the Parisian 'haute couture' for its uniqueness. Our intention is to develop an in-depth study on the elements that make the costumes of this movie so singular, such as its intentional lack of historical accuracy and the ode to an overly exaggerated symbolism and decay.

Keywords: Bram Stoker's Dracula, Eiko Ishioka, Dracula, Costume Design, Francis Ford Coppola.

\section{IV}

Rouge, rouge saigne le soir,

Sur un merveilleux paysage,

J'ai vu un terrible visage

D'un majestueux ange noir.

Red, red bleeds the evening

In a wonderful landscape,

I have seen a terrifying face

Of a majestic black angel.

(Iwan Gilkin, 1892, 78).

\footnotetext{
1 Federal University of São Paulo, Department of Art History, roberto.rodrigues@unifesp.br
} 
For Denis, of course

\section{Introduction}

We wittingly use the word "couture" in this paper's title with the intention of starting this analysis with one of the biggest semantic discussions around costume design: what is the difference between an elaborate costume design and a work of 'haute couture', or when a costume design could have easily been featured on the fashion week's runways of Paris.

In this research, the costume design developed by Ishioka for "Dracula" is considered as an example of when the veil that separates these two categories of fashion design becomes thinner. With a deeper analysis of the current concepts of 'haute couture' and, taking into consideration that its characteristics are already well established and fixed in the society's imagery, we will address the similarities between the work of a 'couturist' and a costume designer who seeks in their creative process to emancipate their garments from the narrative of the film, letting the costumes exist completely independently within each scene.

Ishioka believed in this emancipation and in 'Bram Stoker's Dracula', alongside Francis Ford Coppola, established a second narrative thread, accessible only to those spectators who pay close attention to the signs sewn, embroidered, or studded with mastery and perfectionism in each one of her costumes. Imbued with Western meanings and with a visuality full of caricatured orientalisms, these signs tell us secrets and sometimes even reveal the character's fate, as we will study in a specific case later.

\subsection{Haute Couture}

It is a well-known fact that 'haute couture' is considered a French cultural heritage, being literally a type of quality certificate issued directly by the French Ministry of Industry to 'maisons' that meet a series of specific and currently questionable requirements - often over the top and fanciful - such as the exclusivity of the garments, that must always be unique, made of high standard raw materials and fabrics, have a minimum number of French employees, produced exclusively in Paris and almost entirely by manufacture, just to name some examples.

In his irreverent essay 'Haute Couture et Haute Culture' (Pierre Bourdieu 1983), Bourdieu deals with this theme in a good-humoured way by showing Haute Couture as an example of how to create luxury goods by giving it a mystical aura 
and even sanctifying them somehow, making the garments inaccessible to most consumers and distinguishing them from any other type of clothing production, which is very similar to the intentional strategies of artistic avant-gardes movements,

[...] what is at stake (in haute couture) is the possibility of transmitting a creative power; [...] The fashion designer performs a transubstantiation operation. You have a 'Monoprix' perfume for three francs. The 'griffe' turns it into a Chanel perfume worth thirty times more. It is the same mystery of Duchamp's urinal, which was constituted as an artistic object because at the same time it was marked by a painter who signed it and sent to a consecrated place that, upon receiving it, made it an object of art, thus transmuted economically and symbolically." (Pierre Bourdieu 1983, 7-8).

However, the author confesses later in the same essay that his motivation to analyse specifically the 'haute couture' was driven by his belief that it is "less sacred art" (Pierre Bourdieu 1983, 1-2) than others, such as painting and classical music, since working with these artistic expressions that have already been legitimized by the 'status quo' are somehow protected from scientific criticism as they are endowed with irrational sacredness - which does not happen at all with fashion.

This subjective hierarchy that places some artistic segments over others generally features fashion (and cinema) in "lower" positions in this pseudo ranking due to its wide reach and accessibility, as explained by fashion curator of the Museum of Modern Art (MoMA), Paola Antonelli,

[...] most forms of design, but especially fashion design, are too often considered "lesser" disciplines in the art world (much the way film is), because no matter how extensive the scholarly literature they engender, they still manage to immediately connect and inspire-and usually delightat levels that are accessible by the many as well as by the few (Paola Antonelli 2017, 17).

So, it is possible to understand that, when dealing with cinema and fashion, and especially with their convergence - the costume design - the researchers' approach in treating their subjects as a work of art is already an act of legitimization of such subject and contributes so that such subjects receive a more in-depth and scientific study, instead of the usually shallow, superficial, and market-focused approach.

After this first analysis, we consider the garments designed by Ishioka for 'Bram Stoker's Dracula' as - also - a 'couture' design, exclusively for its originality, 
spectacularization, manufacturing and aesthetic merit, and not by its economic, social, or marketing worthiness.

\subsection{Costume design}

We mainly based our research on the extensive work of Stella Bruzzi (Royal Rolloway, University of London) in her book 'Undressing Cinema: Clothing and Identity in the Movies', 1997.

Both Bruzzi and Ishioka propose an emancipatory analysis of costume design as an artistic, questioning, active and reactive attribute of movies, that goes far beyond the historical, social, or psychological accuracy needed for dressing the characters, with a duality that at the same time "gives the costumes a narrative purpose and allows them to exist independently of that dominant discourse" (Stella Bruzzi 1997, XIII).

Ishioka's idealistic vision about the contribution of the costume designer to a film as an independent process that has its own purposes, which often goes beyond the character, its story and even the very actor who will be wearing the garment,

Costumes should be more than just items that explain the role of the actors who wear them. Costumes must have enough force to challenge the actors, the cinematographer, scenic designer, and director. And at times the costumes should challenge the audience and make them think about why the actor is wearing that costume (Eiko Ishioka, Dracula: The Film and The Legend 1992, 127).

She insisted for scenes to be rewritten and scripts be altered so that her costumes could dominate the set, as seen in the specific case of the dress (Figure 1) designed for the character Lucy Westenra, played by Sadie Frost. Ishioka used the 'frilledneck lizard' or frilled-dragon (Figure 2), a species from the Australian deserts, as a reference for the creation. The idea was to use the dress as part of Lucy's transformation, "Because Lucy turns into a vampire wearing this dress, I wanted to make sure it would look bizarre and haunting after the transformation." (Eiko Ishioka, Coppola and Eiko on Bram Stoker's Dracula 1992, 70). 


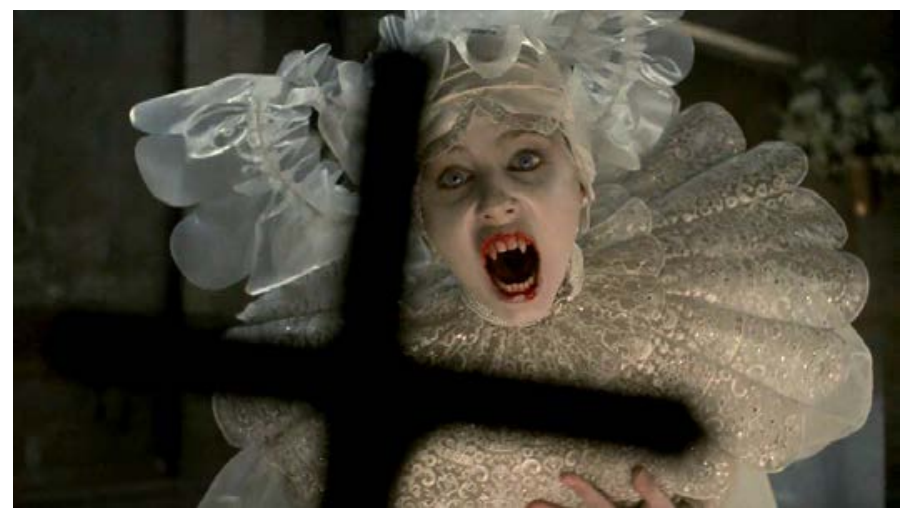

Figure 1. Detail of the "lizard" wedding dress of Lucy Westenra (Sadie Frost).

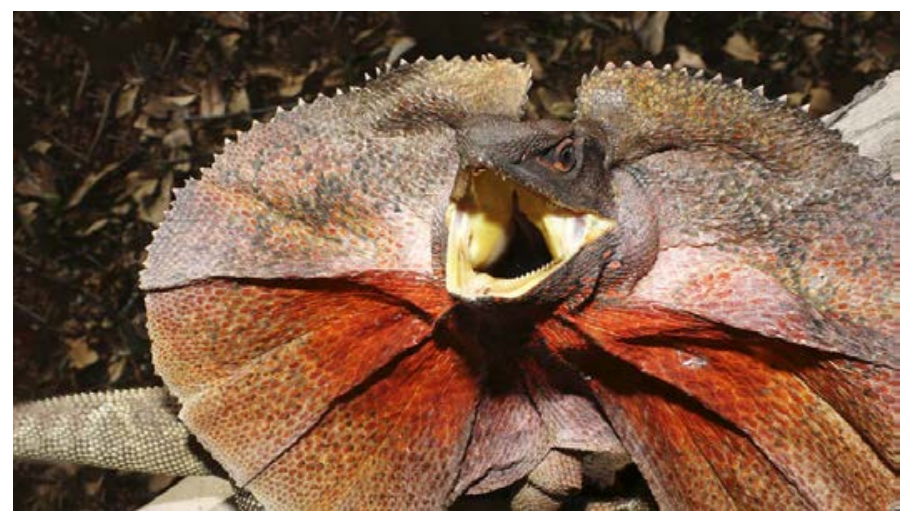

Figure 2. Frilled-Dragon, Australia. Photo by Travis W. Reeder, 2005.

Being a significantly large garment, richly embroidered, the dress - originally a wedding dress, in which the character was later buried due to her tragic fate - was extremely heavy, and was preventing the actress from performing her exhaustively rehearsed choreography routine. Frost and Coppola would like to have the character slide along the walls like the lizard that inspired the garment, using animalistic movements that are very common in other horror movies such as 'The Exorcist' (William Friedkin 1973), which was the director's primary source of inspiration for this scene - that can be noted in the homage to the iconic vomiting scene - as he wrote in his diary (Ibid. 1992, 70).

It was virtually impossible for Frost to move properly within the garment, and Ishioka considered (against her will) creating a completely new design that would allow the scene to run as scripted but left the final decision in Coppola's 
hands. The director, who was already so fond of the dress, preferred to change the scene itself so the dress could still be used in the film. (The Costumes Are the Sets: The Design of Eiko Ishioka. Kim Aubry and ZAP Zoetrope Aubry Productions, 2007).

As we see in Bruzzi,

[...] the distinction between costume and couture design is the belief that clothes can function independently of the body, character, and narrative, that through them alternative discursive strategies can be evolved that, in turn, question existing assumptions about the relationship between spectators and image, not necessarily problematised through the use of conventional costumes (Stella Bruzzi 1997, 3).

On the same page, Bruzzi recounts an example - no less shocking - of when 'couturist' Coco Chanel - well-known in Hollywood for denying changes in any of her costumes designs - signed the costume design for the feature film 'Palmy Days' (A. Edward Sutherland 1931) and created a series of ostensibly identical dresses - with small changes from one to another - so that they were used in specific scenes and would always be perfectly fitted for the character, whether she was standing, moving or sitting, "a subtle way to prioritise the clothes over the narrative" (Stella Bruzzi 1997, 3).

Thus, it is possible to confirm the consonance between Bruzzi's academic point of view and Ishioka's artistic perspective on the main difference between a costume design and a 'haute couture' design. Ishioka's production for 'Bram Stoker's Dracula' managed to bestow upon the film an unique aura, which differentiates it from all productions of the same period, and which to this day, gives the movie its 'canon' status among adaptations from the homonymous novel by Bram Stoker, what can be confirmed by the specialized reviews of the time and the public reception.

\subsection{Reception and reviews}

Film critic Richard Corliss wrote in his column in Times magazine a deep and positive review of the movie in the week of its release, where he praised the reinterpretation of the vampire as a bearer of a "blood curse", precisely in the era of AIDS as a powerful metaphor, humanizing it, and highlighting that

Coppola composes movies as Wagner composed operas, setting primal conflicts to soaring emotional lines. [...] Everyone knows that Dracula has a heart; Coppola knows that it is more than an organ to drive a stake into. (Richard Corliss 1992). 
The film's reception in Brazil was no less enthusiastic. The newspaper Folha de S. Paulo covered its world release on November 13th, 1992, and on November $26^{\text {th }}$ published the news that on the date of its premiere, the film "grossed US\$ 11.2 million, a record for the film industry" at the time (Silvio Cioffi 1992).

In January of the following year, the traditional SET magazine (national edition) published what can be considered a 'Bram Stoker's Dracula's dossier' in a special issue on the movie, which emphasized the strangeness caused by the costumes and characterizations. José Emílio Rondeau was assertive in stating that the film could be considered the most radical cinematographic work of its time, and that forming an opinion about it "requires a definitive conviction [...] love it or leave it" (José Emílio Rondeau 1992).

Both critical and audience acclaim led Ishioka to win the Best Costume Design category at the 1993 Academy Awards, most due to her break with tradition in the visual representations of vampires in film, a rupture that has a real impact on the popular culture of a generation. In 2017, Joe Sommerlad wrote on Indepent about the legacy of her film production,

Ishioka's costumes for star Gary Oldman brought the vampire count to life and freed him from the black cape and evening wear the character had become associated with through iconic Universal and Hammer portrayals by Bela Lugosi and Christopher Lee. (Joe Sommerlad 2017).

However, despite being a key player in the success and acclaim of the film (the only adaptation of the novel to receive four Academy Award nominations and win in three categories: costume design, makeup design and sound editing), Ishioka's work is still treated as secondary, or worse, it gets overshadowed in reviews of that time, and even from nowadays.

The movie's visual merits are almost integrally associated with its director, Francis Ford Coppola - although he praises Ishioka's participation in the entire process of construction of the movie whenever possible.

Using a ten-question form, a survey was carried out at the beginning of the 2020 academic year with 250 students of Human Sciences at the Federal University of São Paulo (Unifesp) who had already watched the feature film at some point in their lives.

Of all the participants, $73.9 \%$ reported sensing a strangeness regarding the characters' costumes, and $95.6 \%$ stated that the costume design is the most striking memory they have of the film since they watched it - with $76.8 \%$ attributing their greatest memory to the costume composed of a huge red cloak and two hair buns, wore by Gary Oldman in Dracula's decrepit version (Figure 3). 


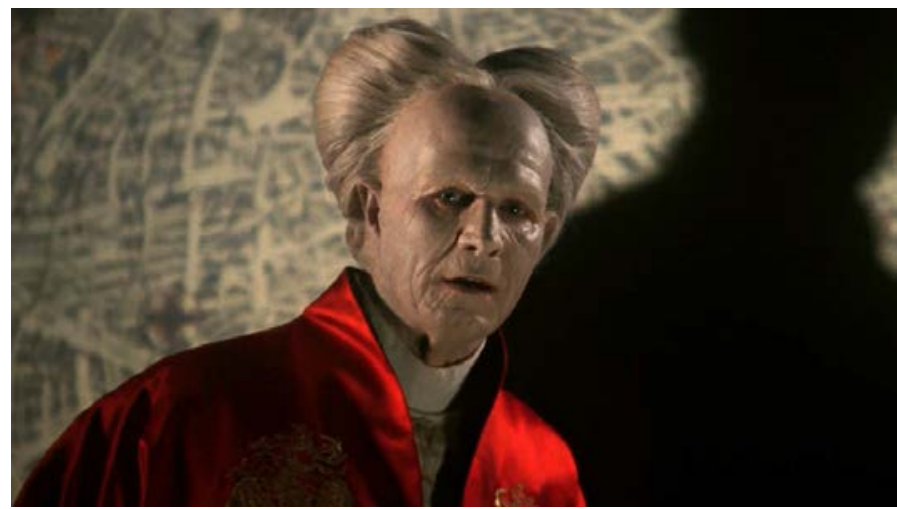

Figure 3. Gary Oldman featured as the eldest version of Dracula at the beginning of the movie.

Still, 74.4\% never questioned who was responsible for creating those garments, $75.2 \%$ were unaware that the film's costume design won an Oscar in the year of its release, and $80.4 \%$ had never heard of Ishioka's name before the survey. At the same time, $94.4 \%$ of them would like to know more about her work after becoming aware that she was responsible for the movie's costume.

It is possible to conclude that such numbers - even if small when compared to the total amount of spectators that the movie has reached since its premiere reveal a patriarchal and occidentalist pattern in the attribution of a film's credits. Thus, the importance of a more in-depth critical and academic study regarding costumes designs is clear - especially those signed by women - and, even more when these costumes clearly have a high complexity and influenced most of the productions that came after it, as is the case of 'Bram Stoker's Dracula', whose costume design freed the iconic figure of Count Dracula from its aesthetic and even philosophical chains.

\section{The costumes are the sets}

The friendship and mutual professional admiration between Eiko Ishioka and Francis Ford Coppola began long before they worked together on 'Bram Stoker's Dracula'. As a graphic designer, Ishioka had been commissioned in 1980 to create a Japanese version of the movie poster of 'Apocalypse Now' (Francis Ford Coppola 1979). Her version ended up becoming the director's favourites and, since then, Coppola had followed her work more closely, like her art direction in the film 
'Mishima: A Life in Four Chapters' (Paul Schrader 1985) and the release from her first book 'Eiko by Eiko' (Eiko Ishioka 1990).

As he ambitioned to create an unorthodox version of Bram Stoker's vampire in film, Coppola believed that Ishioka's completely fresh and oriental visual perspective could cause a sensation of "never seen before" in the audience, in some sort of cultural shock on Hollywood's North American film circuit, "By bringing in Eiko, I knew I was ensuring that at least one element of the film would be completely atypical, absolutely new, and unique." (Eiko Ishioka, Dracula: The Film and The Legend 1992, 126).

On the other side, Ishioka did not feel very comfortable in taking on such a large production and "only" being responsible by the costume design. In her past experiences as a production designer, she was responsible for designing the set, costumes, and lighting, which made her aware by then that if she was responsible for coordinating just one of them, she might not achieve the intended visual result.

The surprise came when Coppola presented to her all his visual references and research for the movie, especially the symbolist masters of the nineteenth century 'fin de siècle'. Beyond that, he assured her that his biggest investment would be in the costume design department, something completely new in the film industry and in Ishioka's own professional background, making her change her mind about whether or not to accept the opportunity, "When Francis told me that the costumes would be the key factor in determining the quality of the film itself, I accepted the job." (Eiko Ishioka, Coppola and Eiko on Bram Stoker's Dracula 1992, 21).

However, by accepting to be part of the project, Ishioka had to suit her own views to the symbolism 'Je ne sais quoi' that Coppola and the film's art directors, Thomas E. Sanders and Garrett Lewis, intentend for the project, completely based on the aesthetic concept of the book 'Dreamers of Decadence: Symbolist Painters of the 1890's (1971), by the French illustrator and art historian Philippe Jullian, who had a very specific point of view on the aesthetics of symbolism and was one of its greatest scholars. Coppola saw in Jullian's work a perfect translation of the concept of "decadent atmosphere" that he wanted to incorporate in his production,

"The twenty-odd years known as the "fin de siècle" ... were dominated by the twin forces of mysticism and eroticism ... This eroticism was displayed with a freedom which astonishes us today, and which helps us to understand Freud, whose ideas were conceived in an environment which now strikes us as sexually obsessed." (Phillipe Jullian 1971, 101)

And, in addition to the decadent symbolism and her own visual references, Ishioka recalled attending some very peculiar requests for the film's characterization that 
were inspired by specific artworks or even entire avant-garde art movements. A memorable example she mentioned in Kim Aubry's documentary was the exclusive request of the director, who wanted at least one of Dracula's costumes to be inspired by Gustav Klimt's 'The Kiss' (Der Kuss, 1907-08) (Figure 4).

To accomplish this task, Ishioka established a relation between the painter's colour palette to the golden Byzantine icons of the Orthodox Church and created a Byzantine "mosaic" cloak with an enormous 'Hodegetria' (Theotokos - Virgin Mary iconography) encrusted right on Dracula's chest (Figure 5). This is yet another example of how the costume design overlapped and even clashed directly with James V. Hart's script, as in the film - as well as in the novel - the character shows a certain sensitivity to Christian religious symbols on several occasions, which happens due to his satanic nature. (The Costumes Are the Sets: The Design of Eiko Ishioka. Kim Aubry and ZAP Zoetrope Aubry Productions, 2007).

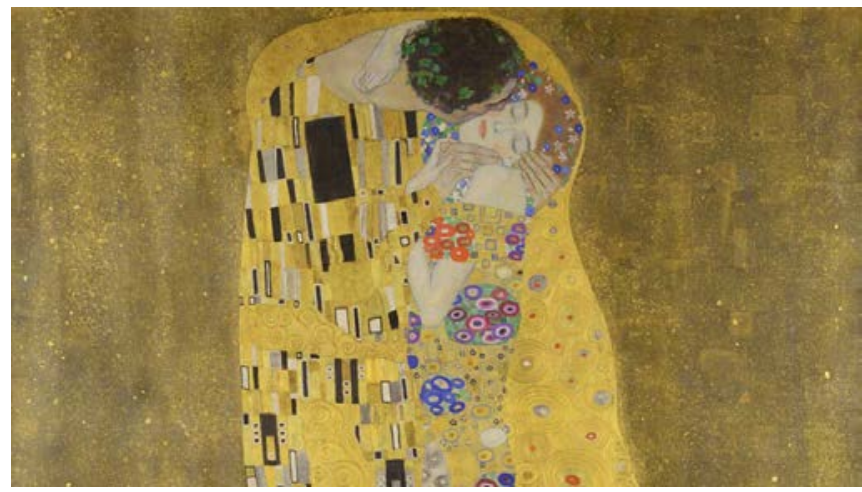

Figure 4. The Kiss (Lovers), Gustav Klimt, 1907-08. Google Cultural Institute.

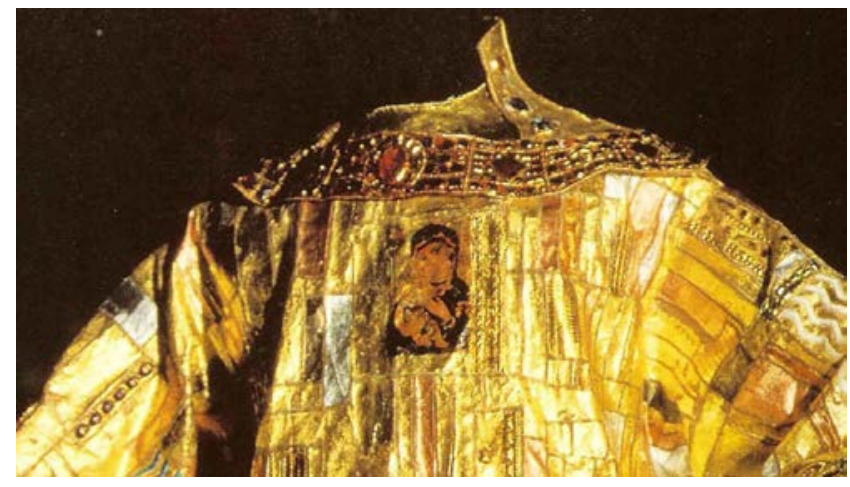

Figure 5. Dracula's golden cloak with a Virgin Hodegetria icon (Detail). 
Another important account of specific requests that Ishioka had to attend to was to present Dracula's three brides as elemental (and voluptuous) muses of the Art Nouveau movement, specifically inspired by the women portrayed by Alfons Maria Mucha (1860 - 1939) (Figure 6). Creating a spectral and ethereal atmosphere, the costume's fabrics give a suggestion of a body, with a wet, fresh aspect and always with wind blowing nearby (Figure 7), but using aged colours and bandages, giving an appearance of horror and decomposition to the dresses, referring to bandages used in mummifications and even the holy shroud. (Eiko Ishioka, Coppola and Eiko on Dracula 1992, 44).

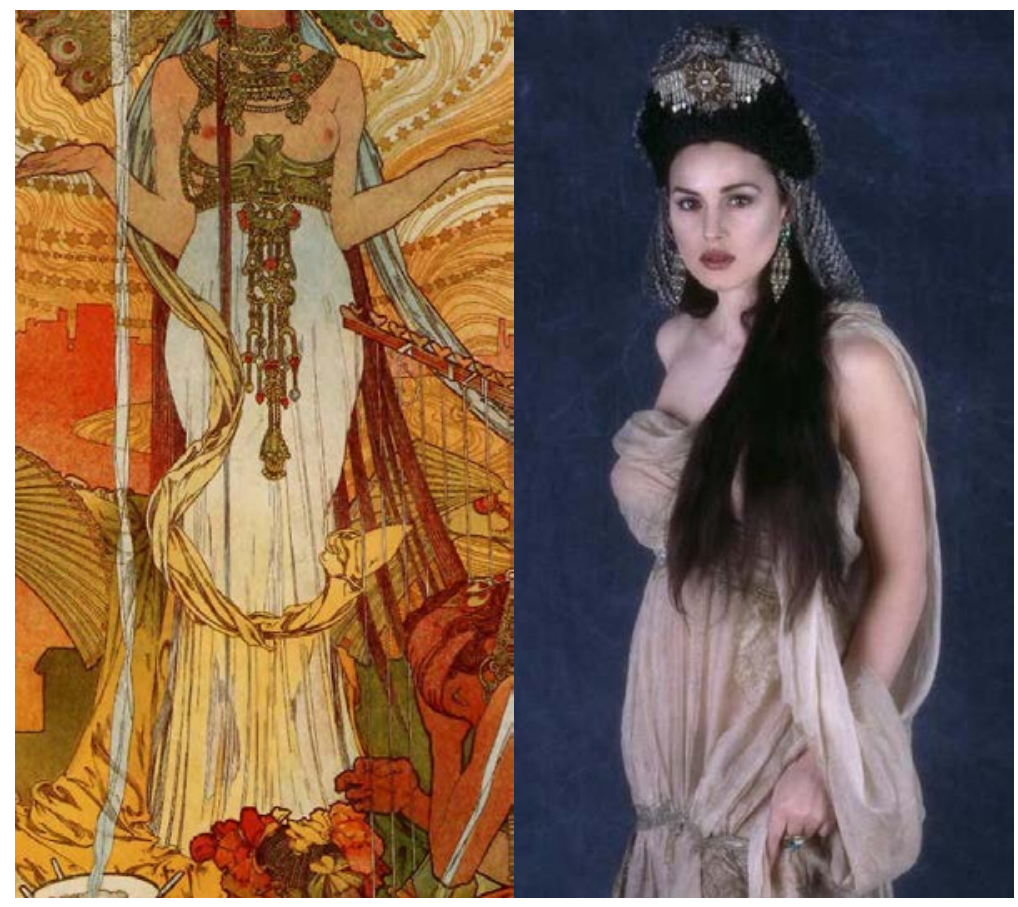

Figures 6 and 7. Salammbô (Detail), Alfons Mucha, 1896 and Monica Bellucci as one of Dracula's bride, 1992.

\subsection{The garments}

One of the greatest achievements of the costume design created by Ishioka is the semantic union between Western and Eastern cultures in garments that often hide more references than their screen time allows us to get. Ishioka did not believe in "literality" in her work. Everything that was designed by her had a multitude of 
layers and references often as conflicting as, for example, the North American western pop culture and the Byzantine Empire, as she states,

With my costumes I aimed for a symbolic reflection of the culture of the characters in the film. [...] Their culture was a hybrid, a mixture of East and West [...] These costumes represent my visual interpretations of this unique union of East and West. (Eiko Ishioka, Ibid. 1992, p.29)

The most memorable feature of her costume designs is the exaggeration, the excess. Ishioka does not try to perfectly recreate an era, style, or colour, instead she pays a symbolic homage by exaggerating recognizable features of a particular period or culture. Regarding this aspect of her work, the article "Eiko on Stage" (author unknown), published in 2001 in issue number 22 of Thresholds magazine, says that Ishioka "stretch[es] boundaries that are simultaneously cultural, disciplinary and historical" (Thresholds 2001).

'Bram Stoker's Dracula' was indeed a cultural breaking point in what is expected of the costume design of a period drama, as it gives a minor role to the multiple possible historical visions of an era, cultural and social differences, and the possibilities of recreating nineteenth-century clothing, which are generally the most important aesthetic guidelines for costume designers in this film category, where the costume establishes some kind of 'implied convention' with the audience, conveying the idea that at a given time people dressed "exactly" like what is shown on the screen, creating a pleasant illusion that allows for a greater emotional connection with the spectators.

That does not happen in 'Bram Stoker's Dracula'.

There is no illusion or an implied convention between spectator and costume designer, on the contrary, there is a vague notion of a certain period, established by mentions of dates through diary entries, which results in some type of caricature of reality, a blurred version with more of a dreamlike - or nightmarish - atmosphere than reality.

Costumes such as those created for Bram Stoker's Dracula, for instance, purposefully borrow from a range of divergent sources that evoque the end of the nineteenth century not through historical specificity but rather through excessiveness. [...] Such examples point to a process of borrowing that actively engages the source through a process of exaggeration as opposed to mimicry. (Ibid, 2001).

Throughout her career, Ishioka was always questioned about the possible lack of historical accuracy in her costumes. Her defence? Entertainment. "The audience 
does not have the needs of a historian, the audience expects some kind of excitement." (Immortals Official Behind the Scenes, 2011).

Among the most identifiable costumes of 'Bram Stoker's Dracula' is the first incarnation of the main character as a medieval warrior. Here we see an idealized version of Vlad III Drăculea and as the audience sets their eyes on the "Impaler", he is perceived as a large, strong, beautiful, and frightening figure.

His armour has an unique pattern - for which Ishioka would be recognized for the rest of her life and would later replicate in the movie 'The Cell' (Tarsem Singh, 2000) - inspired by the raw human musculature, red and bloodless as seen in anatomy books illustrations. The idea was to present an "easter egg" of the halfman, half-wolf monster that Dracula transforms into throughout the film. But, still as a mortal man, this transmutation effect is created by the shapes on top of his helmet, which suggest the ears of a wolf and the half-closed eyes demonstrate his animalistic ferocity (Figure 8).

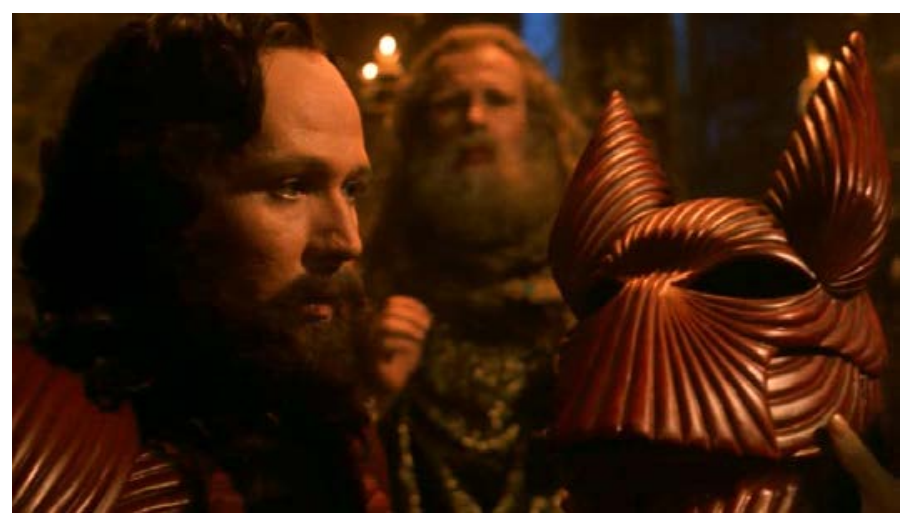

Figure 8. Gary Oldman as the warrior version of Dracula with his 'wolf like' helmet.

I wanted to depict him in his armour as a cross between man and beast, and came up with the stylized muscle armour, like that in anatomy books. The helmet is also stylized muscles, but the effect here is a mixture of a wolf's head and a human skull. Red, the colour signifying blood. (Eiko Ishioka, Dracula: The Film and The Legend 1992, 18).

A possible reference to Dracula's helmet was perhaps very familiar to Ishioka, as her vision of a warrior might have been influenced by the aesthetics of Japanese culture and its Samurai 侍 (Bushi, 武士). Although Ishioka mimics the figure of a hybrid between man and wolf with the armour's helmet design, its resemblance to a “Kabuto (兒, 贯)", the traditional Samurai helmet, is evident, even more so in the 
overlapping layered composition in the back (Figure 9 and 10), known as the Japanese ornament Shikoro (Figure 11).

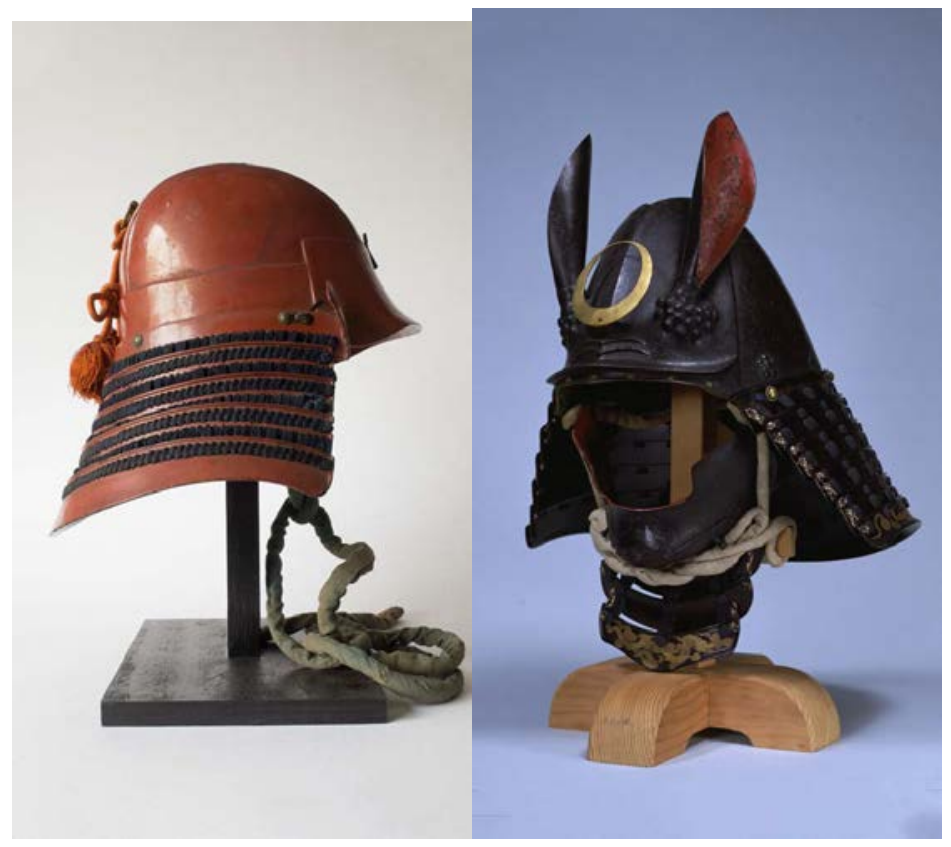

Figures 9 and 10. A red kabuto samurai helmet (Uromachi period 1333-1568) and the kabuto of gusoku (Edo period 1603 - 1868)

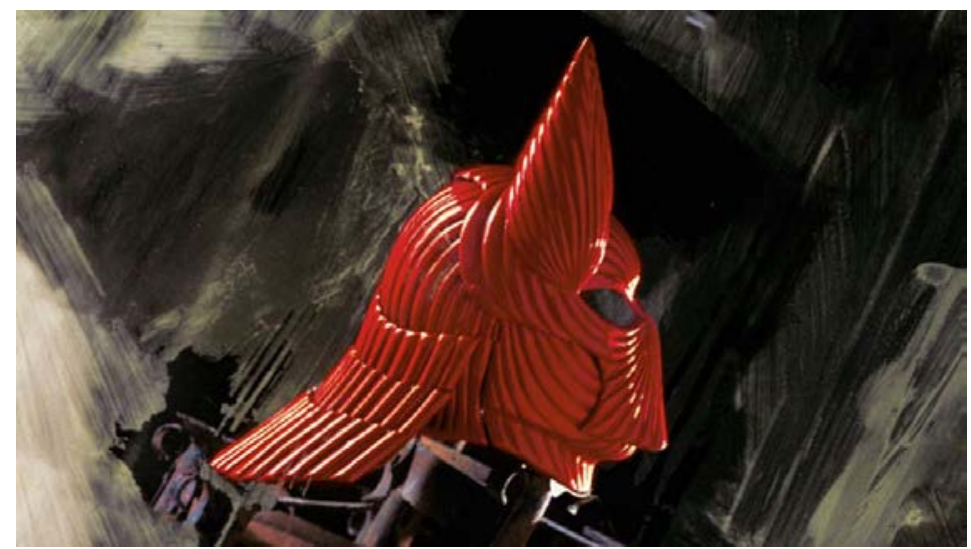

Figure 11. The red 'wolf like' helmet (Detail). 
Another Eastern reference for the characterization of Dracula in his first and second appearances is the possibility that Ishioka was inspired by the Nō 能 or Nōgaku 能楽 Theatre, since the most recognizable features of this traditional style of Japanese drama are its costumes, which completely covers the actor's body, only leaving small traces of humanity visible so that the acting can be performed in key points of the actor's body and movement.

This dramaturgical resource was extensively used by Gary Oldman when inside the armour costume since his movements were practically immobilized. He states that this was the most challenging costume of his entire dramaturgical experience in the film. (The Costumes Are the Sets: The Design of Eiko Ishioka. Kim Aubry and ZAP Zoetrope Aubry Productions, 2007).

About this characteristic of the Nō theatre, Japanese writer Jun'ichirō Tanizaki (谷崎潤一郎) writes in his 1933 essay "In Praise of Shadows" that

[...] the Nō actor performs with no makeup on his face or neck or hands. The man's beauty is his own; our eyes are in no way deceived. [...] Rather we are amazed how much the man's looks are enhanced by the gaudy costume of a medieval warrior a man with skin like our own, in a costume we would not have thought would become him in the slightest. (Jun'ichirō Tanizaki 1933, 44)

The military theme of the Nō theatre, which portrays medieval warriors in their most glorious and dramatic moments, is also suitable for quotation and comparison with the film's medieval epilogue, an ode to the masculinity and virility idealized by Japanese culture, which often flirts with homoeroticism, as will be demonstrated in the next costume design to be analyzed.

It is remarkable the beauty placed in each detail of the romantic couple presented very quickly by the narration at the beginning of the film, and yet our eyes almost exclusively focus on the figure of the warrior that, as well as on the Nō theatre, evokes the struggle, the difficulties faced on the battlefield, which are present from the epilogue until the movie's tragic climax.

The Nō sets before us the beauty of manhood at its finest. What grand figures those warriors who traversed the battlefields of old must have cut in their full regalia emblazoned with family crests, the somber ground and gleaming embroidery setting of strong boned faced burnished by a deep bronze by wind and rain (Ibid., 46).

The next recognizable vision of Dracula could not be more different from the figure of the Samurai warrior of the No theatre, which still resonates in the audience's recent memory. Perhaps this is the most iconic and provocative characterization of 
Dracula, in his older version with a huge red cloak and two monumental white hair buns - now, very different from the 'wolf ears like' top of his helmet. The contrast between one physical representation of the character and another could not be more adverse. Ishioka had a clear intention of causing a disturbance feeling in the audience by the manyfold characterizations of Dracula, which always renews the aesthetic. She explained that "every costume was designed to be totally unique and never seen before, to cause a fresh sensation each time Dracula appeared" (Eiko Ishioka, Dracula: The Film and The Legend, 1992, p.18), a point of view very similar to the definition of haute couture, as we mentioned earlier in this paper, this uniqueness pursued to make an ever fresh and original impression could easily be used to describe a haute couture week in Paris.

In this second incarnation, Dracula is an elderly (Figure 12), exotic, and practically harmless figure. A mix of visual elements compose his costume design, from the hair characterization that is a completely strange reinterpretation of a 'Pouf' or 'Toque' - big white wigs worn by French royalty and aristocracy in the 18th century (Figure 13) - to the garments, which contains an ode to symbolic orientalism, referencing the Ottoman (Figure 14) and Chinese (Figure 15) empires. The dragon family crest designed by Ishioka to compose the garment is a mix of Chinese and Western drawings, and the red cloak evokes the figure of the "Emperor" in Chinese culture, whose symbol is the dragon itself.

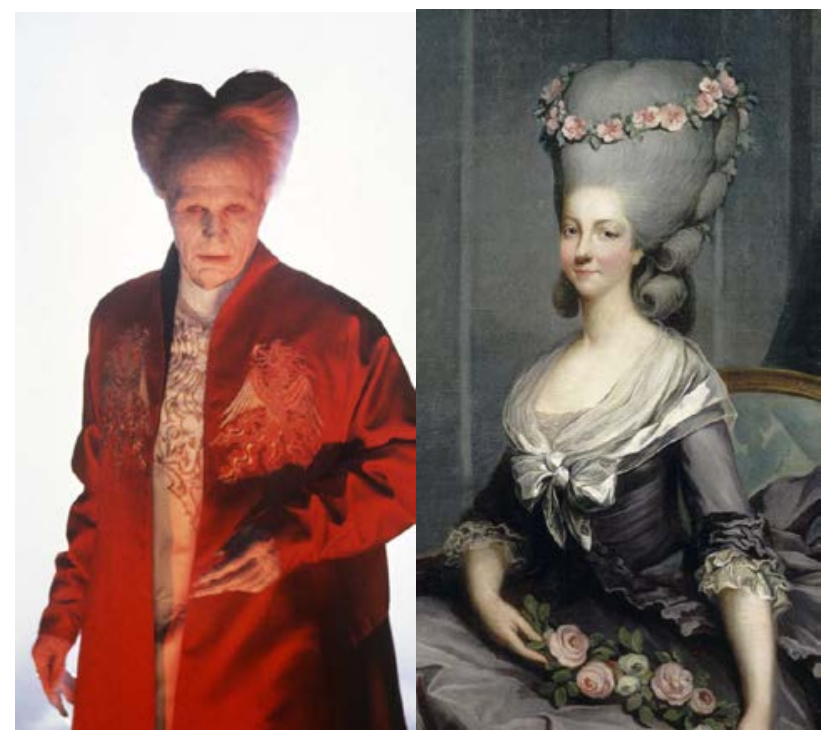

Figures 12 and 13. Eldest version of Dracula as seen in the movie and Madame de Lamballe, Antoine François Callet, c.1776 (Detail). 


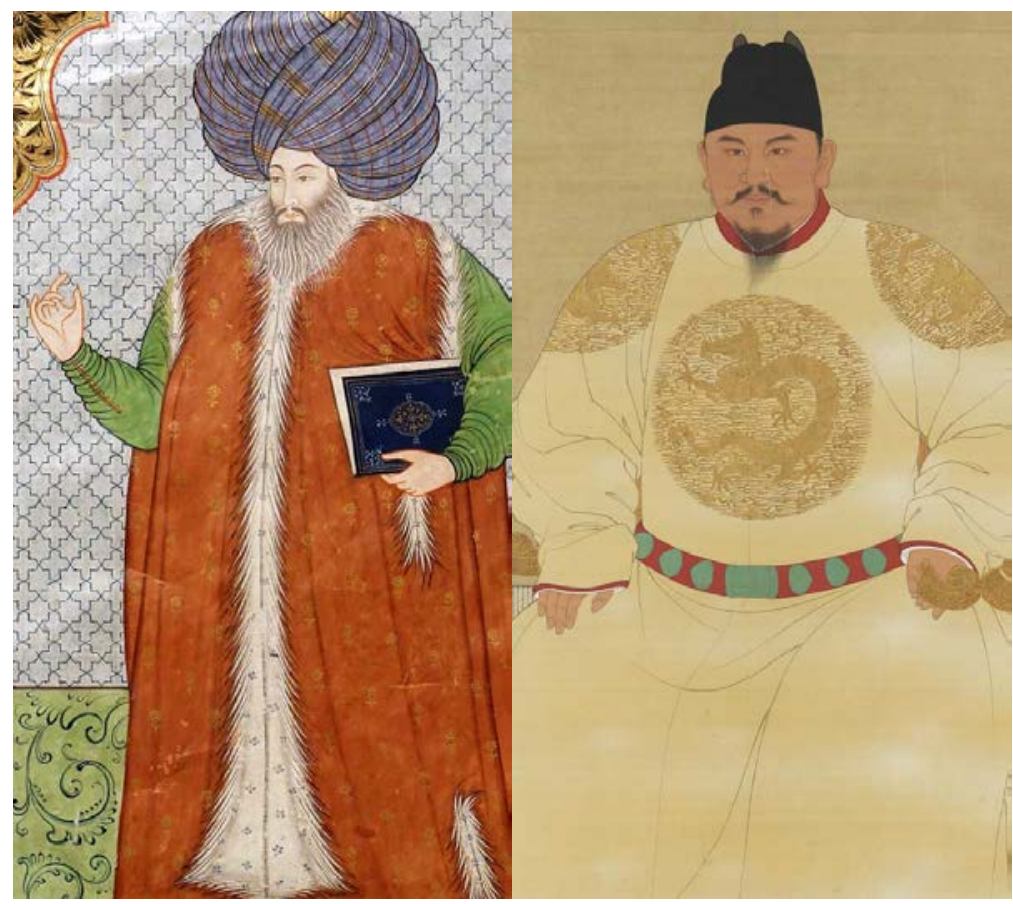

Figures 14 and 15. Ottoman official (c. 1650) and a seated portrait of Ming Emperor Taizu (c. 1380).

In his youth Dracula lived in Istanbul and would have been influenced by Turkish culture and dress, as seen in this costume. [...] The cloak is red [...] The enormous train was designed to undulate, when he rushes about his castle, like a sea of blood. (Ibid, p.38).

Another less subtle difference between the warrior and the older Dracula versions can be seen in the performance of a false softness and femininity, an attempt to emulate an erudite and Victorian upbringing and share the culture of his guest. Dracula exhibits a series of affected behaviours that makes us quickly forget that this creature, that now could easily be mistaken for an elderly woman, had once been a giant and strong medieval warrior, as noted by Keanu Reeves characters (Jonathan Harker) when he sees the warrior painting - inspired by the iconic selfportrait of Albrecht Dürer (German, 1471-1528) (Figures 16 and 17) - and can only spot a slightest similarity. 


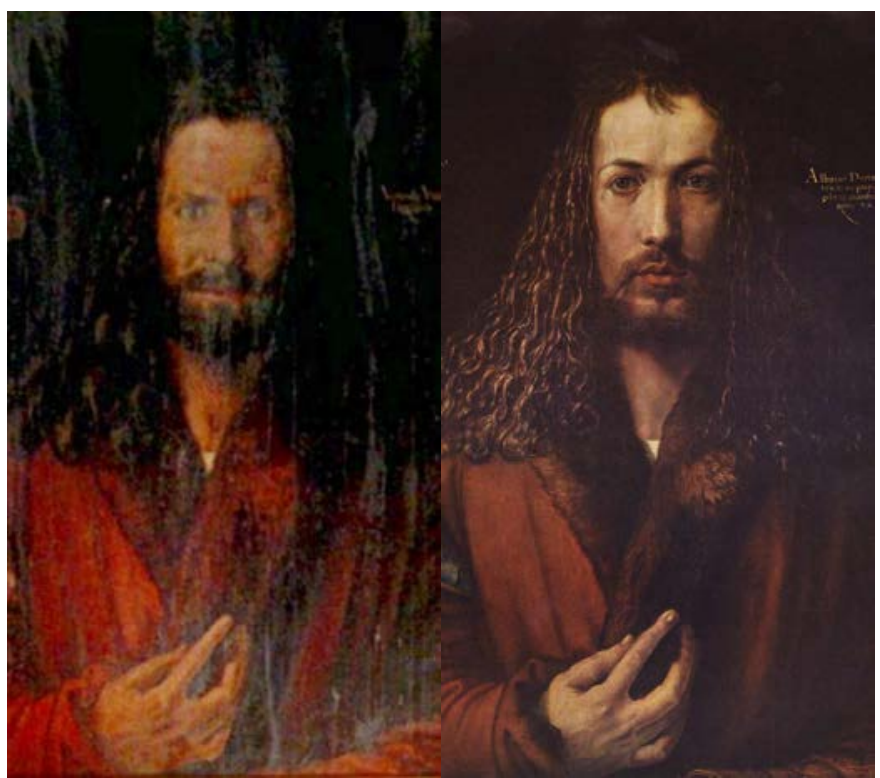

Figures 16 and 17. Dracula's portrait as seen in the movie and Dürer's self-portrait at 28 (1500) (Detail).

I chose to emphasize the androgynous quality in his character. I wanted to give Dracula an infinite variety of personality, so that his true self is not easily revealed, remaining a mystery to the audience. Is he a man or a beast? Devil or angel? Male or Female? He is constantly changing, in a different mood each time, like a kaleidoscope. (Ibid, 38).

In addition to his androgyny, Ishioka explores with this look - in a subtle way - the character's sexuality and gender identity, with "the overall effect of costume, hair, and makeup aimed for a haunting transsexuality "2" (Ibid., 38). This clear and rational intention to cause a general estrangement around the character can be seen, for example, in his cordial expression of interest in his guest. Such interest is read as confusing, suspicious, and ambiguous, alternating between displays of elation, anger, and small delicacies, or even the implied sexual tension between the two characters, which purposely leaves the audience as confused about Dracula's true intentions as Jonathan Harker's himself.

\footnotetext{
${ }^{2}$ Author's note: in both sources that I found this excerpt from Ishioka's interview transcribed, the translation of the word appeared in different ways. In one the word used was 'asexuality', in the other it was 'transsexuality', I chose the one that made the most sense for the paper.
} 


\subsection{Elisabeta / Wilhelmina 'Mina' Harker case study}

When analyzing the costume designs of 'Bram Stoker's Dracula', it is necessary to make unlikely connections between references that usually would never be seen together in an artwork. This unique pool of references in Ishioka's work makes a superficial analysis of her designs practically impossible, since the visuality of a given character is developed by a complex creative process of cultural 'distillation', where Ishioka gives new meaning to images and visualities to create a unique and assertive effect on the film's audience. "Reference is only a reference, I never use a design element straight from the source" (Ibid, 127). Thus, if Ishioka used her visual references literally, without going through this critical distillation process, the effect that a certain garment would have on the audience would be completely the opposite of her primal intention.

The references used for the main character encompass millennia of human visual production, carefully combined to generate contradictory feelings on the spectator each time he appears, another character deeply studied by Ishioka - who set up a real team of professionals to assist her in the production of the costume designs - was Elisabeta / Mina Harker (Winona Ryder).

Ishioka dedicated herself to create a narrative discourse with Mina's clothes that could establish an autonomous dialogue with the audience regardless of the actress' performance or plot, emancipating the costumes from the character. The department created by Ishioka to produce Mina's costume designs had the exclusive work of couturier Dale Wibben, as well as a budget for importing silk Taffetas directly from France and Italy for the creation of the dresses (Eiko Ishioka, Coppola and Eiko on Dracula 1992, 94).

This dedication to Winona's character - that in Hart's screenplay had fundamental importance to understanding the film's narrative and also has a clear role of "Deus ex machina" in its final climax, where we get a glimpse of a version of Paolo and Francesca Da Rimini ${ }^{3}$ (Figure 18) as Vlad and Elisabeta on the celling of the castle (Figure 19) - allowed Ishioka to tell the character's side story, often giving specific directions of her destiny, as seen in her first appearance, still as Elisabeta, Vlad's fictional romantic partner in the film's prologue.

Perhaps Elisabeta is the most important character in the plot. Mentioned in some specific moments in the film, her actual screen time is extremely short and troubled, full of pain and sorrow. We only see this character at cathartic moments throughout the movie.

${ }^{3}$ The tragic story of the adulterous lovers is recounted in Canto $V$ of Dante's Inferno and was a popular subject with artists and sculptors from the late 18th Century onwards. 
In the prologue of the movie, a beautifully planned sequence, shows the final moment where the character, deceived by the Ottoman army, ends up committing suicide (believing that her fiancé, Dracula was killed in battle). Her soul is now doomed to wander eternally between heaven and hell due to her mortal sin, which leads Dracula, a Christian warrior, to prefer the eternal damnation and disown Christ than to spend an eternity in heaven without her.

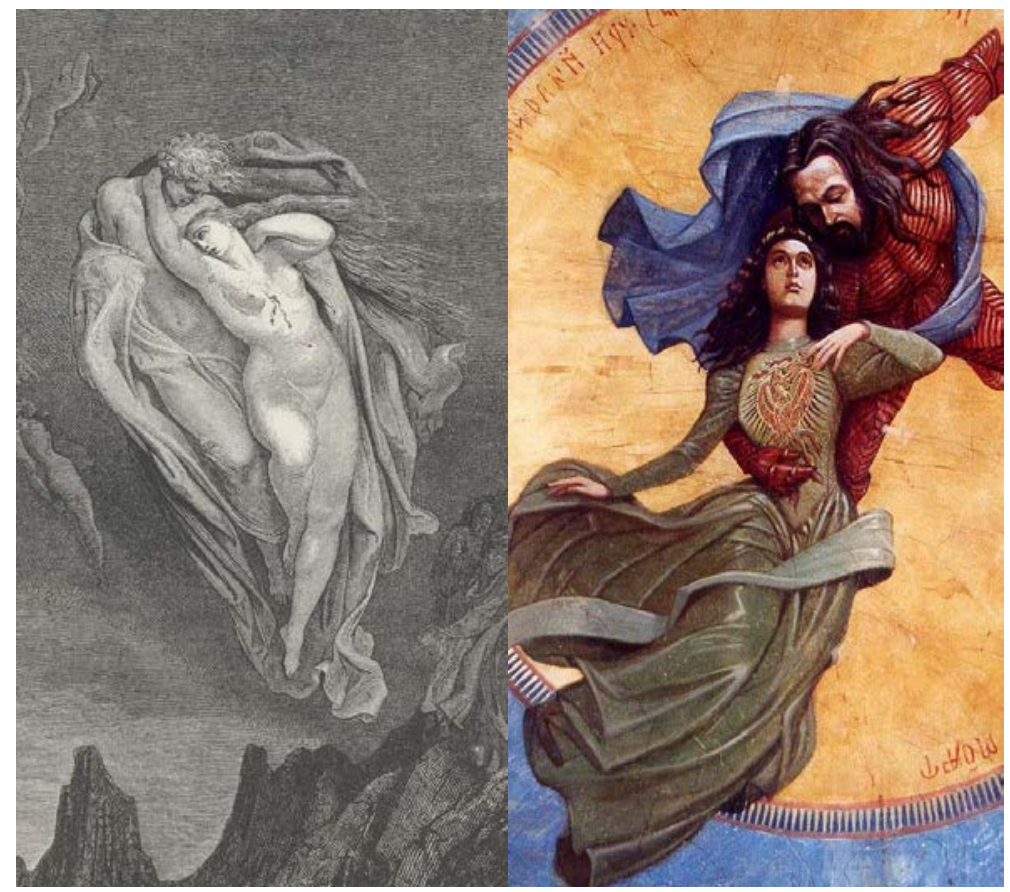

Figures 18 and 19. Canto V of Dante's Inferno, Gustave Doré (circa 1860) (Detail) and a the Fresco of Dracula and Elisabeta as seen in the movie.

Ishioka chose "green" as the predominant colour of Winona's character, be it Mina or Elisabeta, and based on this she started connecting the two characters through their costume designs. Elisabeta has a forest green silk and velvet dress with puffy sleeves and fully embroidered in gold, at first sight with a floral pattern, which matches her crown.

It is important to highlight that there is no certainty or affirmation that Mina is the reincarnation of Elisabeta before the movie's climax. Easily refuted coincidences and light suggestions marks this fundamental part of the narrative. Therefore, the fact that Ishioka filled this gap only with the transition of costume designs from one character to another, and thus delivering this information to 
viewers at the very beginning of the film, is one of her most fantastic and assertive decisions.

Apart from the colour green and floral patterns used in both characters designs, one other thing makes Elisabeta's gown stand out: its richly adorned tail, always positioned in very specific ways for the camera. The floral pattern of the garment soon takes on another meaning and gives the impression that the tail spreads out like peacock's feathers, a Sun bird with daily habits that is widely represented in the symbolist and decadentist movements as well as by the art nouveau, and although its presence among the artist's visual references would make total sense, as seen in this paper, with Ishioka, there is a need to unravel her references and never assume them as literal, as nothing is exactly what it seems until a visual purification is achieved.

The positioning of the tail when Elisabeta's corpse is shown to us (Figure 20) reveals a new referential layer implemented by Ishioka, very connected to the visual representation of the peacock, the Chinese phoenix, Fenghuang 凤凰 (Figure 21), which in its most iconic version takes the form of a chimerical bird with a common pheasant's head and a peacock's tail. It is important to note that the Chinese phoenix is the exact antithesis and female counterpart of the dragon, which represents Dracula, and both sacred animals are auspicious symbols in this culture seen often as a symbol of romantic love.

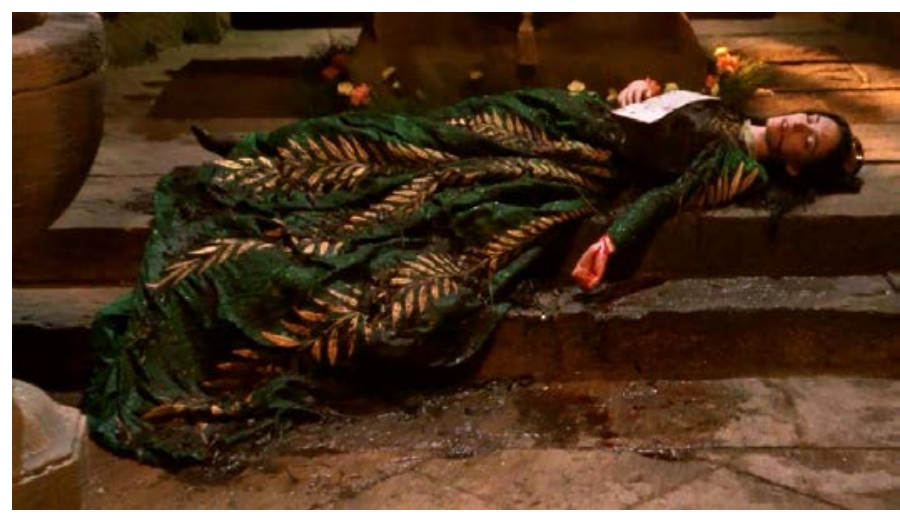

Figure 20. Elisabeta's gown with a tail that resemble a phoenix tail. 
Figure 21. Phénix à neuf têtes, Shanhai jing, Dynastie Qing (1644-1911).

Thus, the western medieval couple is represented by the eastern's dragon and phoenix, this one lacking the resurrection powers of its western version. But if we go one step further into Ishioka's symbolic distillation we can understand that, even though she visually represented a hybrid between floral patterns and the peacock and oriental phoenix feathers in Elisabeta's gown, the artist symbolically endowed such visuality with the resurrection ability of the western phoenix. In a process of resignification, uniting the two mythological creatures into one, she gives the spectator enough material to anticipate that the character will, at some point, resurrect.

In Winona's next scene, now already as Mina (Figure 22), a young woman, fresh and full of love - and desire - for Jonathan, there is the same floral pattern, but this time not yet fully blossomed as in Elisabeta's sleeves (Figure 23), but with tiny buds and small leaves in an almost divine pastel emerald green silk. The dress no longer has the peacock's tail, however, a beautiful scene transition with a real peacock feather (Figure 24) closes the narrative cycle of Elisabeta's dress, showing us - through the connection between these identical symbols - that the character has "resurrected" or "reincarnated". 


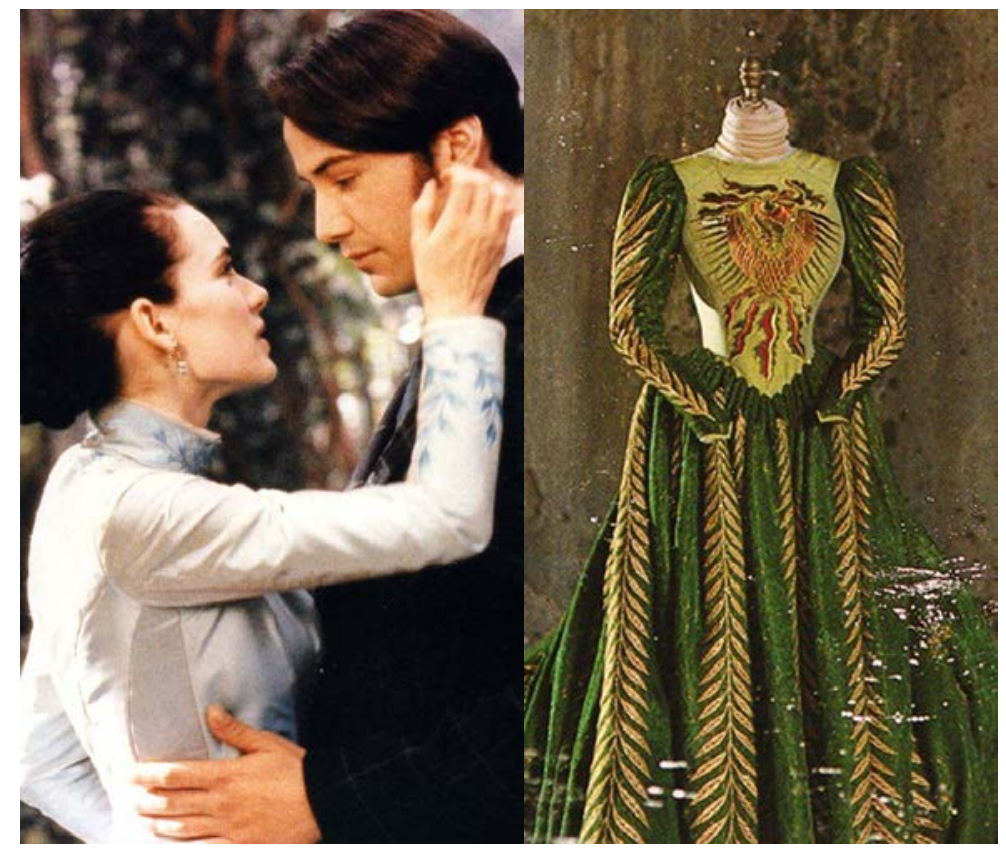

Figures 22 and 23. Mina's floral bud pattern and Elisabeta's floral pattern costume as seen in the movie.

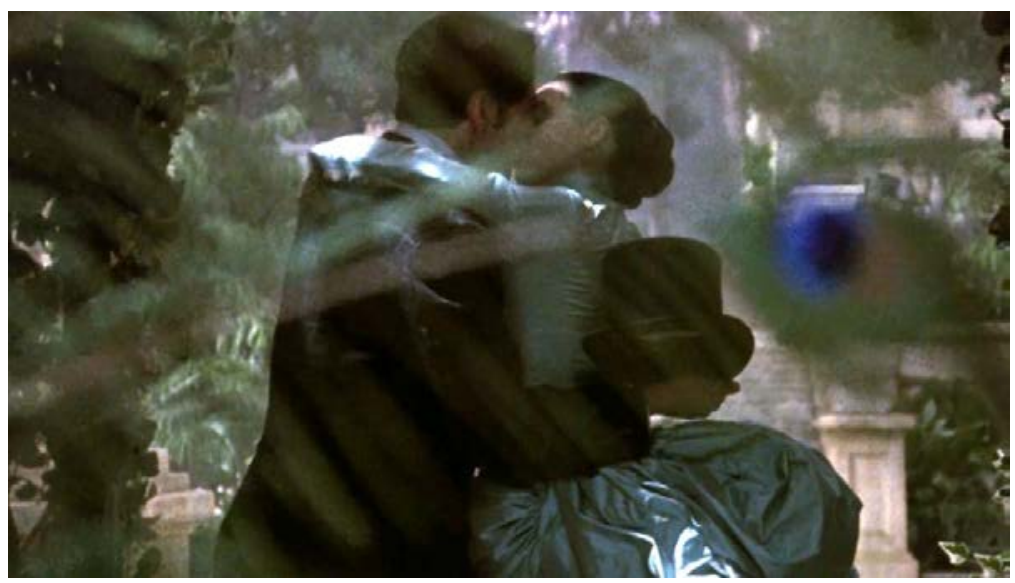

Figure 24. Mina and Jonathan Harker in the aforementioned peacock feather transition scene. 
Bruzzi explains that costumes can often create this parallel narrative and by doing that totally modify the cinematic experience, "the film possess a covert, a codified discourse centered on the clothes themselves". (Stella Bruzzi, 1997, 35). This visual narrative parallel to the main plot, established right at the beginning of the film, is one of the most notable examples of how Ishioka was able to tell a story and even provide the viewer with more information with her costume designs than the movies' predominant discourse.

A clear example of the uniqueness of this artwork.

\section{Conclusion}

When starting this research, our intent was to take a more in-depth look at Ishioka's work in 'Bram Stoker's Dracula'. It is possible to observe that her work transcends the traditional idea of costume design that provides an idealized representation of reality to give the characters some visual credibility.

Her items establish a creative and aesthetic relation closer to fashion design and 'haute couture', with the garments themselves assuming the discourse on stage, almost independently from the actors' performance. Acting autonomously without any intention of providing viewers with historical accuracy, on the contrary, her costumes seek to generate sensations through aesthetic experimentation, characteristics that are very common to works of art.

It is not by chance that these sensations are what the audience will carry for the rest of their lives after watching the movie only once.

Ishioka's disruptive role in contemporary and specifically in horror cinema is undeniable, seeking a new visual interpretation for the image of Dracula already established by other film adaptations. Dracula's image remains unchanged in popular culture (there is even an 'emoji' that still depicts him with his eternal black and red cape like in the 1931 Béla Lugosi's iconic version of the Count).

However, the film 'Bram Stoker's Dracula' has a singular atmosphere, not because of the story, the script, the character, or any 'Manichean' artifice that contributes to its originality, but because its imagetic appeal sets the production apart from others.

It is not just a vampire movie or just a Dracula movie either. It is an exclusive aesthetic experience about possible representations of goth, as we have not seen it since, and is perhaps an unique event in the North American film industry.

The idea of giving independence to the costume designs, matching their narrative importance with the acting, and bringing in an Eastern visual artist with no previous experience in projects of this size, and providing her with the ideal 
environment of creative freedom and financial resources, may have sounded like a risky bet at the time, however, Coppola and Ishioka have an experimentation level and almost scientific rigor on their productions - he because of traumatic experiences in previous movies, such as 'Apocalypse Now' (1979), and she because of her eclectic artistic experience, which permeated almost all media and visual art formats available.

Box office records and industry and critic awards have made Ishioka orbit her career around costume and fashion design, working until practically her last days with household names from both areas, such as Tarsem Singh, Björk and Grace Jones on her famous and groundbreaking Hurricane Tour. With a 'couturist' skills and a complex creative process that made her one of the most accomplished visual artists of her generation, Ishioka managed to connect with Dracula's viewers on an almost psychological level, giving them an experience that will last for a lifetime.

Her work achievement deserves to be increasingly studied and deepened by academic researchers, as there is still a lot to be discovered. "When the audience says, 'This movie would not have been good without these costumes', then the costume designer has succeeded" (Eiko Ishioka, Coppola and Eiko on Dracula, 1992, 29). We can conclude that by her own standards, Ishioka has succeeded.

In memory of Eiko Ishioka (1938-2012)

\section{References}

Antonelli, Paola, Michelle Fisher, Luke Baker, Anna Burckhardt, Stephanie Kramer, Mei Mei Rado, and Jennifer Tobias. 2017. Items: Is Fashion Modern? New York, NY: Museum of Modern Art.

Aubry, Kim. 2007. The Costumes Are the Sets: The Design of Eiko Ishioka. ZAP Zoetrope Aubry Productions, DVD.

Bourdieu, Pierre. 1983. Questões de sociologia. Rio de Janeiro: Marco Zero.

Bruzzi, Stella. 1997. Undressing Cinema: Clothing and identity in the movies. Abingdon: Routledge.

Cioffi, Silvio. 1992 "WHITBY FOI PRIMEIRA A RECEBER O DRÁCULA". Folha de São Paulo, 11/26. Accessed in: 06/12/2021. http://almanaque.folha.uol.com.br/ ilustrada_26nov1992.htm

Coppola, Francis F. 1992. Bram Stoker's Dracula. Universal City, CA: Universal Studios, DVD. 
Coppola, Francis F. and Eiko Ishioka. 1992. Bram Stoker's Dracula: The Film and the Legend. Nova York, NY: Newmarket Press.

Coppola, Francis F. and Eiko Ishioka. 1992. Coppola and Eiko on Bram Stoker's Dracula. São Francisco, CA: Collins Publisher.

Corliss, Richard. 1992. "A Vampire With Heart . . ." Time, 11/23. Access in: 06/08/2021. http://almanaque.folha.uol.com.br/ilustrada_26nov1992.htm

Gilkin, Iwan, Max Waller, Maurice Warlomont. 1892. La Jeune Belgique. Bruxelles: Tome Ozieme. 78.

Ishioka, Eiko. 2001. "Eiko On Stage." Thresholds. Massachusetts Institute of Technology. Dept. of Architecture, Vol. 22: 38-43. Access in: 06/12/2021. https://archive.org/details/thresholds222001mass/page/38/mode/2up?q=ei ko+on+stage

Jullian, Phillippe. 1974. Dreamers of Deacadence: Symbolist Painters of the 1890s. Nova York, NY: Praeger.

Rondeau, José E. 1993. "Sangue e Paixão: O Dracula de Coppola devolve a magia ao cinema". SET Magazine Ed. São Paulo, SP. 14-34.

Singh, Tarsem. 2011. Immortals - Behind the Scenes. Relativity Media, DVD.

Sommerlad, Joe. 2017. “Eiko Ishioka: Celebrating the designer's extraordinary costumes for Bram Stoker's Dracula" in Independent. Access in: 06/08/2021. https://www.independent.co.uk/arts-entertainment/films/news/eikoishioka-japanese-costume-designer-google-doodle-bram-stokers-draculagary-oldman-winona-ryder-francis-ford-coppola-a7836536.html

Tanizaki, Jun'ichirō. 2017. Em louvor da sombra. São Paulo, SP: Companhia das Letras. 